\title{
MARX IN THE SMART LIVING \\ ROOM: WHAT WOULD A MARX \\ ORIENTED APPROACH TO SMART \\ OBJECTS BE LIKE?
}

\section{Betti Marenko and Pim Haselager}

in Marenko, B., Rozendaal, M. and Odom, W. eds. (2021) Designing Smart

Objects in Everyday Life. Intelligences, Agencies, Ecologies. London:

Bloomsbury pp 169-184

\section{Introduction}

When talking about smart objects, the emphasis is often on the user, the experience of interaction, the design of the interface, the UX and so forth. What is not equally addressed is how the system of production of smart/intelligent objects and the organization of the forces of production behind them impacts on the resulting smart experience and environment. A Marxist critique may prove both necessary and desirable to unpack the techno-deterministic narratives of the smart home and, broadly, to recognize that the digitalization of human experience must be addressed as a political issue.

So we ask: what would a Marx-oriented approach to smart objects be like? As an exercise in philosophical thinking - almost 'philoso-fiction' - this chapter has the purpose of mobilizing critical thinking in order to reveal some insights otherwise not accessible. We begin by imagining a smart domestic environment picture, for instance, the living room of a Silicon Valley technocrat populated by connected objects (Nest, Echo, Roomba and the like). In this perfectly plausible domestic landscape we find Karl Marx himself, sitting on the sofa taking notes on his surroundings, exactly as he did in his analysis of the Industrial Revolution.

What would Marx think? We imagine that the smart living room would appear to him as an ecosystem of alienation-inducing commodities. From this standpoint, 
this chapter addresses three main issues. First, the issue of alienation: It can be argued that there is a disjuncture inherent to smart objects. They possess a Januslike quality. On the one hand they support and enable us (the user), and on the other they capture our data, time and attention. In short, they exploit us. While smart environments claim to personalize and tailor their presence to individual needs, at the same time they intrude, monitor and control our life, thus enabling new techno-digital forms of alienation where user, content provider and product all collapse in one single 'datified' dance. These new modes of alienation must be investigated. Second, how do we interpret fetishism of commodities in relation to smart objects? Marx's commodity - a mysterious thing 'endowed with life' describes uncannily smart objects, that is, animated devices with agency. What is needed, then, is an analysis of the systems of (digital) production in order to demystify the 'necromancy' that surrounds the (digital) product of labour. When users become slaves of the very machines they created, we need design scenarios that awaken their users from the alienating slumber induced by this new opium of the people.

\section{Digital Marx}

There are several reasons why Marx is so relevant now, not least the fact that, unshackled by the historical connection to state socialism, his work can be reappraised in its luminous dark futurism. ${ }^{1}$ It is the argument put forward by the present chapter that some of Marx's insights can assist us in unpacking the 'rebirth of the commodity-form in the triumphant language of the digital commodityform' (Kroker, 2004, p 121). From the viewpoint of commodity fetishism, all commodities appear as hyper-sensual objects endowed with the supernatural, mystical, almost occult power to create value (Marx, 1981).

This framework seems particularly appropriate to read the smart objects that populate our environment as digital commodities, enveloped by the very same fetishism that Marx predicted. Likewise, Marx's seminal concept of alienation the fundamental estrangement of the labourer from their labour, from society and from their own human self - seems especially pertinent to describe the contemporary ecologies of cohabitation of human and smart objects, where the role of user and worker increasingly collapse into the same individual.

Marx scholar Christian Fuchs $(2017,2018,2019)$, a vocal proponent of the need to reread Marx in relation to contemporary digital capitalism, argues that Marx's notion of the general intellect 'anticipated the emergence of what some today term informational capitalism or digital capitalism or cognitive capitalism'

${ }^{1}$ For Arthur Kroker, Marx's intuition of the contemporary hyper-realization of the market - is the 'dark future of Capital' (Kroker, 2004). 
(Fuchs, 2018, p. 526). He laments, however, the overall lack of appetite for Marxist theory in the field of media, communication and digital technologies.

The present chapter wants therefore to offer a modest contribution in this sense and, more than filling a gap, offering some insights from the unconventional perspective of a philosopher of design (Marenko) and a cognitive scientist (Haselager) using Marx to reflect on smart objects.

In the context of capitalism in its current mode (whether we call it platform, Big Data, digital capitalism, etc.), 'digital commodities' refer to the commodification of digital labour power, for instance, digital content production, upload and sharing (Fuchs, 2019). ${ }^{2}$ While the nature of digital commodities is increasingly transparent (Negri, 2017), the character of digital capitalism is fundamentally and historically extractive insofar as it mines users' time and attention to turn them into (digital) value. Life itself becomes value-producing digital labour. The extractive character of contemporary capitalism is evident 'not only when the operations of capital plunder the materiality of the earth and biosphere, but also when they encounter and draw upon forms and practices of human cooperation and sociality that are external to them' (Mezzadra \& Neilson, 2017, p. 188).

Take the model of corporate commercial social media, which demands that users create and cultivate social relations alongside an incessant production of content, all the while relentlessly mined for valuable data feeding into targeted advertising. It is this 'free' affective, digital, biopolitical labour that supports the unprecedented gigantic advertising enterprises called Facebook and Google.

The datafication of time, attention and of the whole sphere of living is a new form of capitalist accumulation. ${ }^{3}$ This colonization of human spaces (both interior and social space) is an intrusive process. Take also the way in which a selfless and altruistic activity like 'sharing' has been appropriated and devalued, its meaning profoundly distorted by the rhetoric of social media. Human generosity, kindness and social cooperation have been emptied of their significance and turned into vectors of accumulation of value. This is another aspect of the excavating, extractive and ultimately violent nature of digital capitalism whose aim is the colonization of social relations by digital technology.

As we shall see, the connection between this extractive model and commodity fetishism's faculty to render invisible the social relations of production is evident. Again, take Facebook. While its commodity status may not be immediately clear

\footnotetext{
${ }^{2}$ Fuchs points out the non-rivalrous nature of information, which, as a resource, is not used up when consumed. On the contrary, ease of access, copying, reproduction and sharing indicate that information although highly commodified can also resist commodification. This is the contradiction existing between digital capital and the digital commons.

${ }^{3}$ See here Dallas Smythe's seminal work, who already in 1977 wrote that 'material reality under monopoly capitalism is that all non-sleeping time of most of the population is work time' (Smythe, 1977, p. 3; cited in Fuchs, 2019, p. 61).
} 
as no one pays for access to its platformed sociality, it is precisely this enforced sociality that conceals Facebook's commodity form. Thus, within the sphere of social media, commodity fetishism is inverted. While in its conventional sense commodity fetishism indicates that things (commodities, money) obscure the social relations that have produced them, within corporate social media, social relations become the 'real' experience, possessing immediacy, concreteness and, most important, tradeable value (Fuchs, 2017). In other words, they become a commodity.

\section{Alienation}

Marx saw alienation ('Selbstentfremdung') as the consequence of an objectification and appropriation of labour, which stops being a self-expression but becomes a commodity (McLellan, 2000, p. 86). This applies not only to the product of labour but also to the labour itself: 'Labour is ... not voluntary but compulsory, forced labour. It is therefore not the satisfaction of a need but only a means to satisfy needs outside itself' (ibid., p. 88). The labourer 'does not belong to himself in his labour but to someone else' (ibid., p. 89). Workers get governed by social needs that are alien to them, and 'the greater and more elaborate appears the power of society inside the private property relationship, the more egoistic, antisocial, and alienated from his own essence becomes man' (ibid., p. 128).

Smart objects run the risk of transferring this type of alienation from the work context to the home. Increasingly, the personal life of individuals and families gets orchestrated via virtual assistants or smart speakers like Alexa, AliGenie, Siri or Google home. Smart objects change our home situation from something essentially private into a product to be measured, registered, catalogued, transmitted and exploited. It is well known that some robot vacuum cleaners also function, commercially speaking perhaps even more importantly, as measuring devices of the space they clean, transmitting information about size and location of rooms and possibly even large objects within them (see e.g. Astor, 2017). Such smart objects transform one's living space into a commodity.

The interactions of an individual within the home environment, both with objects and other agents, are registered, collected, analysed, mediated and (at least potentially) directed or controlled by technology. The reasons underlying the willingness to become a data subject at home, to be datafied in one's personal life, are often connected with convenience, ease of use, simplification or externalization of daily tasks and so forth. We suggest that convenience can be seen as a (new) form of wage. In exchange for activities becoming 'easier', one hands over one's private data. But the interaction with smart objects is not a form of self-expression: It is governed by the requirements and opportunities that these artificial agents bring with them. As a consequence, no longer only one's labour 
but also one's private social life becomes alienated. The effects of 'home alienation' through smart objects may leave many traces. It can lead to agency confusions: is the smart speaker an agent? A person? Is it like us, are we like it? Parents report (personal communication) their young children asking, for example, Siri, 'What are you?' Recently, the family of the creator and screenwriter of the TV series 'Black Mirror' decided to remove Alexa after the son addressed his father as 'Alexa' (Tucker, 2019).

Smart objects can lead to more indirect forms of communication. They can also produce altered forms of interaction, like monitoring. The structure of the interaction can get regimented, subtly or less so, through smart objects. An important commercial aspect of smart speakers is to facilitate and stimulate consumption; it is, for instance, highly likely that family communication mediated by smart objects will be nudged towards consumption. Individually, certain capacities may get externalized to such an extent that one's behavioural repertoire, that which one is capable of, may get impoverished significantly or even beyond repair. Anecdotal reports of children interacting with, for example, Siri or Alexa indicate that at some point children ask them to do parts of their homework, for instance, by answering questions about calculations.

But ultimately most fundamental is that the experience of being-at-home will get mediated, transferred into a being-at-home-with-Alexa. This may alienate oneself from the embodied embedded flow of existence in private. Kreitmair, Cho and Magnus (2017) discuss this effect in relation to wearable and mobile health technology, and suggest that

technology may negatively affect one's ability to 'be in the moment'. Experiencing the world and the self in a present, in-the-moment fashion, characteristic of phenomena such as flow, is associated with greater well-being. This requires first-person, introspective means of acquiring self-knowledge. Offloading the monitoring of one's mental and physiological processes onto external technologies is antipodal to such authentic experiencing.

Moreover, they suggest, there is concern that tracking and focusing on external means of gaining self-knowledge may be counterproductive to experiencing phenomena such as 'flow' and 'being-in-the-moment', which may contribute to alienation from embodied and embedded living (Kreitmair, Cho \& Magnus, 2017). The experience, rather than lived, becomes represented and gets processed as such. A similar process occurs in extreme forms of self-quantification, where one's numbers, registered via fitness and food trackers, become more important than how one feels. 'It's a different sort of experience, in that the user is not engaging in an authentic way with reality' (Kreitmair, 2018). It is perhaps worthwhile here to point again to the quote from Marx given above: the 
greater the power of society inside the private property relationship, the more egoistic, antisocial and alienated from their own essence human beings become (McLellan, 2000, p. 128).

Kate Crawford and Vladan Joler (2018) present a remarkable patent owned by Amazon: Hidden among the thousands of other publicly available patents owned by Amazon, U.S. patent number 9,280,157 represents an extraordinary illustration of worker alienation, a stark moment in the relationship between humans and machines (Wurman et al., 2016). It depicts a metal cage intended for the worker, equipped with different cybernetic add-ons, that can be moved through a warehouse by the same motorized system that shifts shelves filled with merchandise. Here, the worker becomes a part of a machinic ballet, held upright in a cage which dictates and constrains their movement." The patent (https://patents.google.com/patent/US20150066283A1/en) contains in Figure 9.1.

We cannot think of any better illustration of Marx's notion of alienation applied to smart objects. Smart objects measure, record, analyse, influence, nudge, steer and direct us. We will live our private lives and go through our intimate social interactions as being carried, measured and restricted by an invisible but effective digital cage in our own homes.

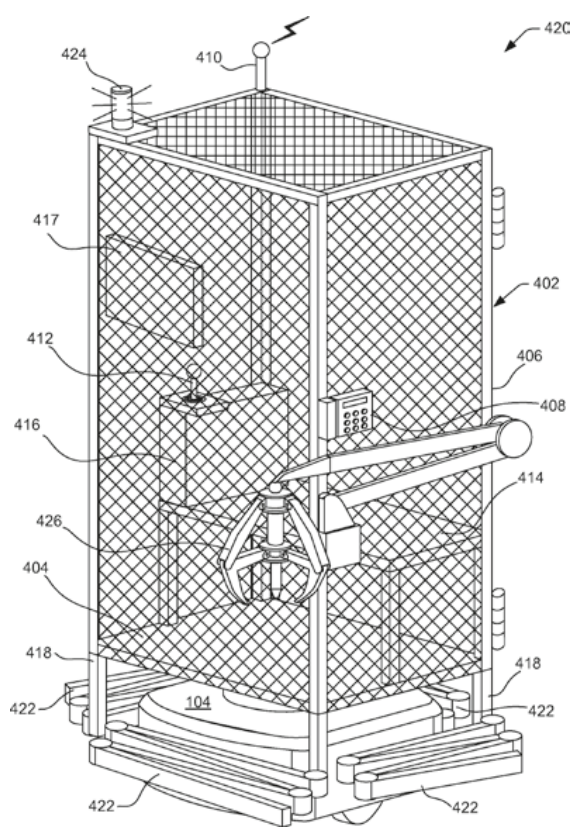

FIGURE 9.1 Amazon patent number 20150066283 A1. 


\section{Marx's commodity fetishism}

In Marx's commodity fetishism, the value of a commodity embodies and hides the human labour that has created it. The commodity assumes 'the fantastic form of a relation between things' (Marx, 1981, p. 165). Thus, commodities appear to have simply emerged as independently animated, sensuous things populating the world with a definite social character. Commodities become social entities, as such able to enter into social relations not only with humans but also among themselves, beyond the world of humans. For Marx, commodities become free agents that relate 'socially' to each other but retain independence from their producers, effectively building a mystical world in which they appear to be alive, uniquely mobilized by desire.

Marx appropriated the term 'fetishism' at an early stage of his career, at a time when the literature on fetishism and the concept itself were relatively new, and pushed it beyond the confines of its received meaning. In an article dated 1842, the young Marx describes fetishism as 'the religion of sensuous desire' (Marx \& Engels, 2012, p. 22), as if mocking the European ruling classes as perverse idolaters and worshippers of inanimate things. ${ }^{4}$ The emphasis on 'sensuous desire' is crucial to an understanding of Marx's concept of fetishism and its legacy, as it foregrounds the affective dynamics of human desire seeking immediate gratification through material objects.

In Charles de Brosses's original formulation (1760; see Pietz, 1993, p. 138 n. 56), fetishism is a primitive form of religion based on the worship of artefacts, a way of thinking that attributes supernatural reasons to contingent facts and sees divine powers in terrestrial entities. Sixteenth-century European traders and colonizers would use the word 'fetish' to describe those artefacts that local tribes from the western coast of Africa would not trade as, allegedly, objects of worship. From this (Eurocentric, positivistic) perspective, fetishism was 'the pure condition of un-enlightenment' (Pietz, 1993, p. 136). On the other hand, fetishism may be interpreted as the projection of European colonial mindset and fears (McNally, 2011). What the colonizers found incomprehensible was the irreducibility of African artefacts to a price: their incalculability. Without a price there was no exchange value: These objects were out of bound, literally un-tradable. Such a refusal to trade, revelatory of the historicity and variability of market laws, had to be reframed as a perversion - a 'fetish'. Without this manoeuvre, capitalism would have had to be acknowledged as an historical phenomenon, a contingent, rather than natural event, therefore not as unavoidable as it is taken to be. ${ }^{5}$

\footnotetext{
${ }^{4}$ For Marcel Mauss, the notion of fetishism contains an 'immense misunderstanding between two cultures, the African and the European' (cited in Pietz, 1993, p. 133 n. 42).

${ }^{5}$ One may wonder what Donald Trump's attempt to buy Greenland says about the convergence, at least in the US president's mind, of capitalism with the fetishism of a specific kind of commodity: real estate.
} 
Indeed, the key point in Marx's theory of commodity fetishism is that the 'materiality of "value" is not physical but social' (Pietz, 1993, p. 145). Commodity fetishism is ultimately an inversion process, namely the inversion of the relations between humans and things: As things are personified, people are objectified. Marx's genius was in understanding that capitalism is about relations (and their inversion) rather than material things, and that at the core of this process lies the enigma of fetishism.

This is exactly where Marx's actuality lies. He understood that capitalism is not about things, but about relations. Moreover, he predicted with uncanny accuracy the double shift, from production to consumption first, and then on to capitalism itself as the pure vector of circulation of technology (Kroker, 2004) - what we will call throughout digital, platform, Big Data or surveillance capitalism. ${ }^{6}$

\section{The fetishism of technology}

Marx, the great futurologist, recognized that fetishism is beyond things in themselves and resides in the fundamental immateriality of value. This has become strikingly evident more so in digital capitalism where everything (time, attention, experiences, life itself) is commodified and value is fetishized precisely because they (time, attention, experiences, life itself) are immaterial.

Marx's fetishism of the commodity can be reappraised to defamiliarize our understanding of technology and to therefore grasp differently modern technological objects with their apparent autonomy and agency (Hornborg, 2012, 2014). While money, commodities and machines are all equally fetishes as 'they mystify unequal relations of exchange by being attributed autonomous agency or productivity' (Hornborg, 2014, p. 121), what distinguishes machines is the extent to which they are often conceptually framed by a techno-determinist narrative, that is, the idea of technology as an inevitable progress over time. Put differently, technological innovation is perpetually disguising the conditions of its production, which is why technological development is presented as a natural progress rather than as capitalist accumulation, inequality and exploitation. This teleological view obscures the fact that any 'rationale of mechanization is inextricably intertwined with global differences in the price of labor and resources' (ibid., p. 122). Far from being a natural progression in innovation, technology (every technology in fact) is 'contingent on specific global constellations of asymmetric resource flows and power relations' (ibid., p. 122). It can therefore be argued that the 'fetishism of technology represents a specific mode of mystifying unequal exchange' (ibid., p. 134) based on the denial of appropriation and on novel processes of

\footnotetext{
${ }^{6}$ Kroker uses many terms to describe late capitalism: virtual, speed, digital, hyper, streamed capitalism.
} 
accumulation which have shifted from extracting value from physical labour into the new extractive territories of time, attention and life as a whole.

Now, if we take this perspective to look at a few examples of smart objects, for instance, digital home helpers such as Nest, Echo or Roomba, what emerges is the extent to which these devices signal a new, hypertrophic mode of commodity fetishism where the key aspects delineated above take on digital specificity. To start with, the rhetoric of dematerialization is already built-in in these device. Narratives of immateriality frame technology as a magic event, with the 'smartness' experienced as a seamless, even supernatural, occurrence. This can happen precisely because the materiality of the digital is hidden. With their emphasis on design and performativity, smart devices continue to hide the process of production, the exploitation and the power relations that have made them possible. But there is another aspect to consider: the compulsive tactility (all that swiping, tapping, pinching, scrolling) that smart objects demand from users produces a repetitive, obsessive, even morbid, fetishistic attachment to devices.

\section{The fetishism of artificial intelligence (AI)}

A case in point is AI. If we take AI as a particular kind of commodity, then here the process of fetishization reaches new heights.

First, AI is fetishized as a technology. Enveloped in dominant techno-

deterministic and techno-positivistic discourses, AI becomes an autonomous force with its own instrumentality - and teleologically projected, like all other technologies. Second, AI relies on hidden digital infrastructures which maintain the illusion that this technology is truly 'artificial' - that is, unhinged from historicity, humanity and contingency. In this sense the fantasy of a self-generating

AI with its propelling rhetoric of self-governing automation is the embodiment of textbook commodity fetishism. Not only are the producers and consumers of digital smart objects unrelated and indifferent to each other. More to the point, the fetishization of AI brings to its apex the dark future of capital envisioned by Marx.

As historian of science Simon Schaffer reminds us when he describes Charles Babbage's automatic machines, 'to make machines look intelligent it was necessary that the sources of their power, the labor force which surrounded and ran them, be rendered invisible' (Schaffer, 1994, p. 204). This original displacement of the labour behind machines is perpetuated by contemporary smart objects.

Commenting on the queues of customers camping overnight in front of Italy's soon-to-open largest Apple store (in Bologna), collective Wu Ming observes how 'putting the largest possible distance between upstream and downstream is the quintessential ideological operation under capitalism' (Wu Ming Foundation, 2011). It is this exploitative (and unseen) scaffolding that supports the soothing narratives of dematerialization, cloud and the internet as the ultimate 
phantasmagoria of unlimited communication, unbound opportunity and limitless freedom. Digital capitalism depends equally on this hidden labour and theoretical scaffolding as well as on the denial of this dependency.

Amazon Mechanical Turk, for instance, is a platform outsourcing to humans what computers cannot do very well (i.e. image labelling and classification). Its menial, repetitive labour shows that the intellectual, cognitive and immaterial Post-Fordist - labour that creates the software needed to power our smart objects has virtually no value without the - still very Fordist - labour needed to manufacture hardware. 'Without factory workers and their labour, no valorisation of digital commodities, no Apple stock quote would be possible' (ibid.).

As the smooth surfaces of our laptops and our smartphones seduce us into an increasingly seamless, frictionless and increasingly infantile experience of interaction, they obfuscate the work and the resources that enter into its production. It is important to remember that these resources are both human and non-human: bodies, energies, materials, minerals, lives, time. This has an effect at once enrapturing and mystifying. As streams of data flow incessantly across our black screens, the world seems to be magically present before us, and made for us. What we no longer grasp in this spell-binding unmediated reality are the forces of production, the property relations, the debt and the profit, the relations of power, in one word, the profoundly violent asymmetry that moulds the digital experience appearing on screen, which is then cloaked by a truly mystical, supernatural, magic character.

An example of this is how the smart home is conventionally advertised through the rhetorical devices of magic and enchantment. In a commercial for the Beko connected Home ${ }^{7}$ that would appeal to Harry Potter's fans, soothing music accompanies the images of two children playing in and with a smart environment that appears to be orchestrated by them but in reality catalogues and orchestrates the way they play, interact and, of course, consume. It is telling that the human delivery employee is made almost invisible. 'Smartified' domestic appliances showcase their functioning by in-real-time indexicality through metrics and icons that even a child can read. Smart objects must communicate with the users at all times. The fetishization of the home environment as 'smart' - that is, as responsive, pre-emptive, subservient - disguises under its reassuring and enchanting cloak a purposeful 24/7 tracking machine.

\section{The aura of digital objects}

Digital objects possess a specific kind of aura. They are predicated on the illusion that they are pieces of everyday magic. Their aura is a hiding mechanism that

${ }^{7}$ Retrieved 3 March 2021 from https://www.youtube.com/watch?v=cJmA6eXZmAg. 
coalesces the rift between the product and everything/everybody that was necessary to its production (human, labour, earth resources, capital, exploitation). The 'superficially mysterious, perfect nature of the digitally manufactured, its magical aura — works to obscure the underlying physical reality of the digital and its subservience to human choices and agency' (Betancourt, 2015, p. 180).

In his critique of the inexorable march of automation, Michael Betancourt (ibid., p. 34) talks about 'the bifurcation between design and facture, one where the devaluation of human labor reaches its apogee: rendered obsolete by the machine, there is no longer any need for human agency once the autonomous factory has been built except to switch it on'. Betancourt argues that in the automation of the modes of production of digital objects, human labour involved in production thins out, and only the human-as-designer remains as the only aspect of non-machine agency. For him, it is inherent in the ideology of automation that 'the productive human population appears obsolete, parasitic, on the "designers" whose plans they formerly executed' (ibid., p. 34).

The totalizing discourse of automation, then, on the one hand tends to conceal the very material labour involved in its making - both in the lifecycle of digital objects (from the miners and the metal-scavengers, to the Silicon Valley janitors, Deliveroo and Uber platoons servicing digital elites) and in the endless labour of content generation. On the other hand, the endless search for anticipatory design and the ultimate seamless interface pinpoint to the increasingly subservient role of design within the techno-digital oligopoly - framed by techno-deterministic narratives about 'neutral' technology.

For Betancourt, digital capitalism should be called 'agnotologic capitalism' - a capitalism based on the systemic production and maintenance of ignorance, designed to confound, misconstruct and misinform. This agnotological order is fundamental to digital capitalism as it generates self-sustaining fictional value bubbles (e.g. dotcom, subprime property) while maintaining a narrow and strictly patrolled horizon for the social networks agents and their production of immaterial assets.

This is a process that constrains potential, pre-empts choices and predicts the future on the ground of past behaviours. It is what philosopher Antoinette Rouvroy aptly calls the regime of 'algorithmic governmentality' (2016, p. 6). It is this agnotological order that 'maintains its grip on the social: managing the emotional states of the consumers who also serve as the labor reserve is a necessary precondition to the management of the quality and range of information' (Betancourt, 2015, p. 207). Again, the extraction of time, attention, life - the biopolitical paradigm of extractive capitalism - is systemically enabled by the hidden structures that keep social agents in their simultaneous roles as users, consumers, producers and designers perpetually occupied, enduringly productive and caught in the digital snare 24/7. As we shall see in the next section, Marx already foresaw this metamorphosis of labour into both product and force of production well over 160 years ago. 


\section{Did Marx foresee automation?}

There is a section in Marx's unfinished rough-drafted notebooks called Grundrisse (literally 'outlines') where the German thinker sketched some remarkably prescient ideas concerning the role of machines in the future development of capitalism (Marx, 1973). ${ }^{8}$ What Marx lucidly describes in this section (known as the 'Fragment on Machines') is the way in which the machine engulfs and subsumes labour. The worker's skill set and even virtuosity honed in the course of many hours are no longer relevant. It is not the worker that makes the machine function; rather it is the machine that uses the worker's own labour as its raw combustible. 'It is the machine which possesses skill and strength in place of the worker, is itself the virtuoso, with a soul of its own' (Marx, 1973, p. 693).

Like workers need food to sustain themselves, so the machine's perpetual motion and animation are sustained through a constant ingestion of raw material. To Marx's list of matières instrumentales (coal, oil, etc.) we ought to add the coltan, niobium, tantalum and all the minerals needed to power digital devices and smart objects. But another raw material must be added to the list: the life power materialized in the continuous data stream that contemporary digital machines demand, and harvest from, their users.

If we substitute the word 'worker' with the word 'user' in the quotation below, we have accurate description of life in the universe of digital capitalism: 'The worker's activity, reduced to a mere abstraction of activity, is determined and regulated on all sides by the movement of the machinery, and not the opposite' (Marx, 1973,

p. 693). As labour becomes 'a conscious organ, scattered among the individual living workers at numerous points of the mechanical system' (ibid., p. 693), it is absorbed by the machine, which turns into a living system made of 'insignificant' individuals. Marx already saw how the transformation of the means of living labour into a mere living accessory of machinery signals a specific moment of the development of capital - the moment when labour becomes both product and the force of production. Marx anticipated that this metamorphosis of labour, far from being an accidental moment in the history of capital, is its foremost necessary tendency, which effectively reshapes labour into a new form adequate to its needs. Seen through the lens of our contemporary smartified landscape, this is an accurate description of the triangulation user-producer-consumer we saw earlier, which turns time, attention and life itself into labour in order to extract value from them. The 'Fragment on Machines' is also where Marx discusses the notions of 'social brain' and 'general intellect'. As living labour becomes absorbed by the machines,

\footnotetext{
${ }^{8}$ Written in the winter $1857-8$, these workbooks were lost for many years and were published for the first time in German in 1953, although a limited edition was published in 1939 in Moscow. Only in 1971 a partial version was made available in English.
} 
capital sustains itself by the continuous 'accumulation of knowledge and of skill, of the general productive forces of the social brain' (Marx, 1973, p. 694). Not only do machines become the most appropriate form of capital; most significantly it is the general social knowledge (i.e. the social brain or general intellect) that becomes the force of production and product. This subsuming of the general intellect to the needs of the machine dictates how social life is constructed. How we live, the very conditions of human existence, in its multitude of social forms, are all dictated by what the machine demands.

The enforced multitasking that brings a user to be force-labour, product and producer comes with a remarkable paradox, lucidly explained by media theorist Geert Lovink (2019), that is, the seemingly pathological indifference of contemporary digital users to relinquishing data for the sake of speed, convenience and instant access. This is not a matter of ignorance (or not reading terms and conditions). It is rather a profound lack of concern that prompts (us) users to sign up for profiles knowing perfectly well what it is traded in the process. As the value of commodities resides (beyond their material sensible qualities) in their exchange value, for Marx the very soul of the commodity far from tangible becomes a ghost, a spectre. In this sense digital commodities are the culmination of the process of fetishization.

\section{Conclusion}

Marx notes how the progression of automation is ostensibly due to science and technology growing capacity at the service of capital enterprise. However, the pivotal element is the manoeuvre of 'dissection that through division of labor gradually transforms workers operations into more and more mechanical ones, so that at a certain point a mechanism can step in into their places' (Marx, 1973, p. 704). Mechanized, automated, atomized, workers' lives are appropriated by the machines in their entirety and in a 'coarsely sensuous form; capital absorbs labor into itself -"as though its body were by love possessed" ' (ibid.). ${ }^{9}$ In his famous 'Manifesto of Machinism' Italian designer Bruno Munari wrote,

Today's world is a world of machines. We live among machines, they help us with everything we do in our work and recreation. But what do we know about their moods, their natures, their animal defects, if not through arid and pedantic technical knowledge?

Machines reproduce themselves faster than mankind, almost as fast as the most prolific of insects; they already force us to busy ourselves with them, to spend a great deal of time taking care of them; they have spoiled us; we have to keep them clean, provide them with nourishment and rest, continually attend to them and meet their every need. In a few years' time we will become their little slaves.

${ }^{9}$ The quotation concluding Marx's paragraph is from Johann Wolfgang von Goethe's 'Faust'. 
Munari wrote these words over eighty years ago and he was well aware of the danger of fetishizing technology. Indeed, he then goes on saying that machines must become works of art, and as a counterpoint to the Futurist adoration of machines he then started building his famous useless machines. Useless machines 'do not make anything, they do not eliminate labour, they do not save time and money, and they do not produce any commodities ... [they are] objects to look at in the way one looks at a drifting group of clouds after spending seven hours inside a factory full of useful machines,' he says. Munari's useless machines intend to provoke us, poetically and imaginatively, to think about not only how we interact with smart objects but also how we can reimagine our whole relationship with them.

This paradox of automation was already evident to Marx. In spite of the reduction of human labour required by machines, there is never 'extra' disposable time for idleness, rest and personal growth. Instead, more and more (indeed all) time is plunged back into maximizing production. Workers (aka users) no longer own their own time. Machines have appropriated it. Users, in turn, have become slaves of the very machines they have created.

\section{Bibliography}

Astor, M. (2017, 25 July). Your Roomba may be mapping your home, collecting data that could be shared. New York Times. Retrieved 26 September 2019 from https://www.nytimes. com/2017/07/25/technology/roomba-irobot-data-privacy.html.

Avent, R. (2018, 27 June). A digital capitalism Marx might enjoy, MIT Technology Review. Retrieved 30 April 2020 from https://www.technologyreview.com/s/611480/adigital-capitalism-marx-might-enjoy/.

Betancourt, M. (2015). The Critique of digital capitalism: An analysis of the political economy of digital culture and technology. New York: Punctum Books.

Crawford, K., \& Joler, V. (2018). Anatomy of an AI system. Retrieved 26 September from https://anatomyof.ai/.

Fisher, E. (2015). How less alienation creates more exploitation? Audience labor on social network sites. In C. Fuchs \& V. Mosco (Eds), Marx in the age of digital capitalism (pp. 180-203). Leiden: Brill.

Fuchs, C. (2014). Digital labor and Karl Marx. New York: Routledge.

Fuchs, C. (2017). Marx's capital in the information age. Capital \& Class, 4(1). 51-67.

Fuchs, C. (2018). Karl Marx \& communication @ 200: Towards a marxian theory of communication. TripleC: Communication, Capitalism \& Critique, 16(2), 518-534.

Fuchs, C. (2019). Karl Marx in the age of big data capitalism. In D. Chandler \& C. Fuchs (Eds), Digital objects, digital subjects: Interdisciplinary perspectives on capitalism, labor and politics in the age of big data (pp. 53-71). London: University of Westminster Press.

Fuchs, C., \& Sandoval, M. (Eds). (2014). Critique, social media and the information society. New York: Routledge.

Fuchs, C., \& Fisher, E. (Eds). (2015). Reconsidering value and labor in the digital age. Basingstoke: Palgrave Macmillan. 
Fuchs, C., \& Mosco, V.(Eds). (2015). Marx in the age of digital capitalism. Leiden: Brill.

Hornborg, A. (2012). Global ecology and unequal exchange: Fetishism in a zero-sum world. London: Routledge.

Hornborg, A. (2014). Technology as fetish: Marx, Latour, and the cultural foundations of capitalism. Theory, Culture and Society, 31(4), 119-140.

Kreitmair, K. (2018). The seven principles for ethical consumer neurotechnologies. The Neuroethics Blog. Retrieved 26 September 2019 from http://www.theneuroethicsblog. com/2018/04/the-seven-principles-for-ethical.html.

Kreitmair, K., Cho, M., \& Magnus, D. (2017). Consent and engagement, security, and authentic living using wearable and mobile health technology. Nat Biotechnol, 35, 617-620. Retrieved 3 March 2021 from https://www.nature.com/articles/nbt.3887?platform=hootsuite\#citeas.

Kroker, A. (2004). The will to technology and the culture of nihilism: Heidegger, Nietzsche and Marx. Toronto: University of Toronto Press.

Lovink, G. (2019). Sad by design: On platform nihilism. London: Pluto.

Marx, K. (1973). The 'Fragment on Machines'. In Grundrisse: Foundations of the critique of political economy (pp. 690-712). London: Penguin.

Marx, K. (1981). The fetishism of the commodity and its secret. In The capital: A critique of political economy, Volume 1, Part 1, Chapter 1, Section 4 (pp. 163-177). London: Penguin.

Marx, K., \& Engels, F. (2012). On religion. Mineola, NY: Dover Publications.

Mason, P. (2018). Why Marx is more relevant than ever in the age of automation. New Statesman. Retrieved 26 September 2019 from https://www.newstatesman.com/ culture/2018/05/why-marx-more-relevant-ever-age-automation.

McLellan, D. (2000). Karl Marx selected writings. Oxford: Oxford University Press.

McNally, D. (2011). Monsters of the market: Zombies, vampires and global capitalism. Leiden: Brill.

Mezzadra, S., \& Neilson, B. (2017). On the multiple frontiers of extraction: Excavating contemporary capitalism. Cultural Studies, 31(2-3), 185-204.

Munari, B. (1937). Manifesto del Macchinismo. Arte Concreta, 10, 15 December, Milano. Retrieved 3 March 2021 from https://www.panarchy.org/munari/munari.html.

Negri, A. (2017). Marx and Foucault. Cambridge: Polity.

Pietz, W. (1993). Fetishism and materialism: The limits of theory in Marx. In W. Pietz \& E. Apter(Eds), Fetishism as cultural discourse (pp. 119-151). New York: Cornell University Press.

Rose, X. (2017). Marxism 2.0: New commodities, new workers?. International Socialism, 154. Retrieved 3 March 2021 from http://isj.org.uk/marxism-2-0-new-commodities-newworkers/.

Rouvroy, A. (2016). The digital regime of truth: From the algorithmic governmentality to a new rule of law. La Deleuziana, 3 (with Bernard Stiegler). Retrieved 3 March 2021 from http:// www.ladeleuziana.org/2016/11/14/3-life-and-number/.

Sandoval, M. (2015). Foxconned labor as the dark side of the information age: Working conditions at Apple's contract manufacturers in China. In C. Fuchs \& V. Mosco (Eds.), Marx in the age of digital capitalism (pp. 350-395). Leiden: Brill.

Schaffer, S. (1994). Babbage's intelligence: Calculating engines and the factory system. Critical Inquiry, 21(1), 203-227. 
Terranova, T. (2000). Free labor: Producing culture for the digital economy. Social Text, 63(182), 33-58.

Tucker, G. (2019, 4 August). Konnie Huq interview: Alexa has made family life with Charlie Brooker just like Black Mirror. Sunday Times. Retrieved 26 September 2019 from https:// www.thetimes.co.uk/article/konnie-huq-interview-alexa-has-made-family-life-with-charliebrooker-just-like-black-mirror-2nw7plcvp.

Wittel, A. (2012). Digital Marx: Toward a political economy of distributed media. Triple C: Communication, Capitalism \& Critique, 10(2), 313-333.

Wu Ming Foundation (2011). Fetishism of digital commodities and hidden exploitation: The case of Amazon and Apple. Retrieved 3 March 2021 from htpp://www.wumingfoundation. com/giap/.

Wurman, P. R., Barbehenn, M. T., Verminski, M. D., Mountz, M. C., Polic, D., Hoffman, A. E., et al. (2016). System and method for transporting personnel within an active workspace. US 9,280,157 B2 (Reno, NV, filed 4 September 2013 and issued 8 March 2016). Retrieved 3 March 2021 from http://pdfpiw.uspto.gov/.piw?Docid=09280157. 